\title{
Effect of Aging on Left Ventricular Function by Real Time Three-Dimensional Speckle Tracking Echocardiography \\ Youssef Fathy Nosseir ${ }^{1}$, Mahmoud Hassan Taha El Arousy ${ }^{2}$, Mohamed Moanes Mohamed \\ Mohey El Din', Muhammad Mahmoud Sameh Muhammad Mahmoud ${ }^{1}$ \\ ${ }^{1}$ Departemnt of Cardiology, Faculty of Medicine, Al Azhar University, \\ ${ }^{2}$ Departemnt of Cardiology, Islamic Centre of Cardiology, Al Azhar University
}

\begin{abstract}
Background: Three-dimensional echocardiography (3D-Echo) has been incorporated into routine clinical practice in many echocardiography laboratories, as it provides many advantages in the evaluation and study of heart diseases. Objective: To estimate the maximum normal systolic reference value of AS in a sample of healthy subjects. Patients and methods: This study was conducted in the Islamic Cardiology Centre in Al Azhar University, Real Time 3D Speckle Tracking Echo data set was acquired over 24 months in 90 healthy subjects divided into 3 main groups according to their age: 1- First Group 16-30 years old, 2- Second Group 31-50 years old and 3-Third Group 51-65 years old. Results: II and age group III were $-22.07 \pm 1.48 \%,-19.40 \pm 1.98 \%$ and $-17.67 \pm 1.52 \%$ respectively. Our study showed that the mean Global Longitudinal Strain at age group I, age group II and age group III were $-19.2 \pm$ $1.52 \%,-18.9 \pm 1.96 \%$ and $-17 \pm 0.99 \%$ respectively. The present study showed that the mean Global Area Strain at age group I, age group II and age group III were $-29.1 \pm 1.31 \%,-28.5 \pm 1.76 \%$ and $-28.1 \pm 1.65 \%$ respectively. Our present study showed excellent intraobserver reproducibility of the results and an overall acceptable interobserver reproducibility of strain measurements.

Conclusion: Global area strain derived from three-dimensional speckle-tracking may be applied clinically as a supplementary diagnostic method since strain imaging can identify LV dysfunction earlier than conventional methods. This opens a new perspective in heart failure prophylaxis and primary prevention with institution of therapeutic measures before the patients develop symptoms and irreversible myocardial dysfunction.

Keywords: Aging, Left Ventricular Function, Real Time Three-Dimensional Speckle, Tracking Echocardiography.
\end{abstract}

\section{INTRODUCTION}

Three-dimensional (3D) speckle-tracking echocardiography (STE) is an emerging technology used to quantify left ventricular (LV) function. However, the accuracy and normal values of LV strain and twist using 3D STE have not been established in a large group of normal subjects. The aim of this study was to establish age-related normal values of LV strain and torsion using real-time 3D echocardiographic (RT3DE) images ${ }^{(\mathbf{1})}$.

Speckle-tracking echocardiography (STE) allows the quantification of left ventricular (LV) global and regional function, which provides clinically useful information in different clinical scenarios ${ }^{(2)}$.

Because of inherent limitations of twodimensional (2D) speckle-tracking for the analysis of LV mechanics, recent investigational efforts have shifted to speckle-tracking analysis using real-time three-dimensional (3D) echocardiographic (RT3DE) data sets. 3-10 Validation of 3D STE has been performed in animal studies using sono micrometry as the reference standard and in simulated models and in vitro as well ${ }^{(3)}$. However, the validity of 3D STE in human subjects has yet to be determined because of the lack of a noninvasive reference standard. Also, the establishment of normal values of 3D speckle tracking echocardiographic parameters over a wide range of ages is important before using this new technology in clinical investigations, to be able to: (1) detect subtle LV dysfunction in patients with normal LV ejection fractions, (2) investigate the effect of drug therapy on LV mechanics, and (3) evaluate LV function during serial follow-up studies ${ }^{(2)}$.

3D STE derives several parameters, including longitudinal, circumferential and radial strain, as well as a combined assessment of longitudinal and circumferential strain, termed area strain. 3D STE can also quantify LV rotational movements such as rotation, twist, and torsion. 3D STE provides a better insight on global and regional myocardial deformation. Main applications include detection of subclinical myocardial involvement in heart failure, arterial hypertension, dyssynchrony, and ischemic heart disease ${ }^{(4)}$. Threedimensional STE is a new technology used to quantify LV global and regional function ${ }^{(5)}$. Theoretically, 3D STE should be more accurate than 2D STE, because the speckles are confined within the pyramidal volume scan. In this manner, 3D STE should eliminate the confounding effects of through-plane myocardial motion, which may affect the accuracy of LV strain measurements using 2D STE ${ }^{(6)}$. However, the lower temporal and spatial resolution of RT3DE could adversely affect the accuracy of 3D speckle-tracking echocardiographic measurements in patients with data sets at the lower range of frame rates ${ }^{(7)}$.

Area Strain (AS) stands out as a particularly novel method with a high potential for clinical applications. This new parameter combines an analysis of both the longitudinal and circumferential deformation 
of the left ventricle. This provides an estimate of the subendocardial surface deformation, which is inversely proportional to the radial deformation (systolic thickening and diastolic thinning) of the ventricular wall, and is the first area of the endocardium to be affected in several different cardiopathies. In other words, 3D tracking of myocardial displacement can be broken up into the 3 spatial axes: longitudinal, circumferential and radial, in the case of the left ventricular myocardium. Comparing the displacement of 2 different points, we can obtain information regarding myocardial deformation or strain in each of these 3 different directions. By combining 2 of these directions, we can observe a surface. By combining longitudinal and circumferential deformation in a given segment of the myocardium, we can obtain the deformation of the subendocardial surface, which is inversely proportional to the deformation of the myocardium in the third dimension (in this case, the radial one) ${ }^{(8)}$.

\section{AIM OF THE WORK}

\section{The aims of this study were to:}

1- Validate 3D speckle-tracking echocardiographic measurements of LV strain.

2- Establish references values of the principal components of LV strain, as well as twist and torsion, using RT3DE and 3D speckle-tracking echocardiographic analysis in different age groups of normal subjects.

\section{PATIENTS AND METHODS \\ Patients:}

This study was conducted on 90 healthy subjects in the Islamic Cardiology Centre in Al Azhar University. Real Time 3D Speckle Tracking Echo data set was acquired over 24 months. The individuals were divided into 3 main groups according to their age:

1- First Group 16-30 years old.

2- Second Group 31-50 years old.

3- Third Group 51-65 years old.

Global LV longitudinal, circumferential, and radial strain were acquired as well as global and regional strain, twist and torsion were measured in same 90 healthy subjects using 3D Speckle Tracking Echo.

\section{Study Subjects:}

90 normal subjects (mean age, 43.4 years old, range, 1665 years, 61 male subjects \& 29 female subjects) were enrolled to obtain RT3DE data sets.

\section{Eligibility criteria included:}

(1) Normal blood pressure with no history of hypertension.

(2) Absence of diabetes and/or any cardiovascular disease. Subjects who were primarily university students $\&$ employees, their relatives and some volunteers. All subjects underwent physical examinations and 2D echocardiographic evaluations to exclude valvular heart disease and/or wall motion abnormalities.

\section{Ethical approval:}

The Ethics Committee of the University approved the study protocol and signed informed consent was obtained from all subjects.

\section{RT3DE Imaging:}

A (GE Vivid E 95) with a 2.5-MHz probe.

Studies were performed by experienced cardiac sonographers with subjects in the left lateral decubitus position. Full-volume data sets were acquired from the apical transducer position during held end-expiration. To ensure the inclusion of the entire LV volume within the pyramidal scan volume, data sets throughout one cardiac cycle were acquired using wide-angle mode, four wedge shaped sub-volumes were acquired with electrocardiographic gating during a single 5-sec to 7sec breath-hold. The mean frame rate of RT3DE data sets was $20.7 \quad 6 \quad 5.6$ frames/sec (range, 11-48 frames/sec).

\section{D STE Analysis:}

RT3DE data sets were analyzed using 4D LV analysis software (GE Imaging Systems) by an experienced observer. From the 3D full-volume data sets, the apical four-chamber, two-chamber and longaxis view as well as one short-axis view were automatically extracted.

Non foreshortened apical views were identified by finding in the data set views with the largest LV longaxis dimensions from the apex and the mitral valve. LV boundaries were initialized by specifically selecting specific anatomical landmarks (i.e., the mitral annulus and the LV apex), after which the 3D endocardial surface was automatically reconstructed. The papillary muscles were included in the LV cavity.

Manual adjustments of the endocardial surface were performed as necessary. Subsequently, 3D speckle tracking analysis was automatically performed through the cardiac cycle.

The left ventricle was automatically divided into 16 segments using standard segmentation schemes. The software provided segmental longitudinal, circumferential, radial, and 3D strain time curves, from which peak global strain and averaged peak strain at three LV levels (basal, mid-ventricular, and apical) were determined. Three-dimensional strain describes the tangential deformation and is calculated as the vector sum of the longitudinal and circumferential strain components, ignoring the radial component.

The 3D speckle-tracking echocardiographic software also generated LV basal and apical rotation angles and LV twist time curves, from which peak basal rotation, peak apical rotation, peak LV twist and peak 
LV torsion (defined as peak LV twist divided by the distance between the basal and apical slices at enddiastole) were automatically measured.

To determine the effects of age on LV rotation and twisting, data describing basal and apical LV rotation in each subject were exported to a spreadsheet to obtain average $\mathrm{LV}$ rotation and twist curves.

To adjust for inter-subject differences in heart rate, the time sequences were normalized to the percentage of systolic and separately, diastolic duration.

To achieve this goal, in each patient, end-systole defined by aortic valve closure as seen on a pulsed-wave Doppler flow profile across the LV outflow tract was set to be $100 \%$ of systolic time.

Similarly, diastolic timing was normalized in each patient by diastolic duration (i.e., end-diastole was set to be $100 \%$ of diastolic time, irrespective of heart rate). This temporal normalization allowed inter-subject comparisons and averaging of the rotation time curves obtained from multiple subjects.

\section{Statistical analysis}

Recorded data were analyzed using the statistical package for social sciences, version 20.0 (SPSS Inc., Chicago, Illinois, USA). Quantitative data were expressed as mean \pm standard deviation (SD). Qualitative data were expressed as frequency and percentage.

The following tests were done:

- A one-way analysis of variance (ANOVA) when comparing between more than two means.

- Chi-square $\left(\mathrm{X}^{2}\right)$ test of significance was used in order to compare proportions between two qualitative parameters.
- The confidence interval was set to $95 \%$ and the margin of error accepted was set to $5 \%$. So, the pvalue was considered significant as the following:

- Probability (P-value)

- P-value $<0.05$ was considered significant.

- P-value <0.001 was considered as highly significant.

- P-value >0.05 was considered insignificant.

\section{RESULTS}

Table (1): Clinical characteristics in the study group $(\mathrm{N}=90)$

\begin{tabular}{|l|c|}
\hline & Range $($ Mean \pm SD) \\
\hline Age (years) & $16-65(43.4 \pm 12.5)$ \\
\hline Gender & $61(67.8 \%)$ \\
Male & $29(32.2 \%)$ \\
Female & $61-106(75.2 \pm 13.4)$ \\
\hline HR (beats/min) & $106-167(126.7 \pm 22.7)$ \\
\hline Systolic BP (mmHg) & $58-115(75.2 \pm 17.5)$ \\
\hline Diastolic BP (mmHg) & $1.41-2.43(1.9 \pm 0.3)$ \\
\hline BSA (m2) & \\
\hline Echocardiographic & \\
parameters & $42-58(52.37 \pm 2.47)$ \\
LVEDVI $(\mathrm{mL} / \mathrm{m} 2)$ & $22-38(31.76 \pm 3.72)$ \\
LVESVI $(\mathrm{mL} / \mathrm{m} 2)$ & $55-79(68.27 \pm 5.41)$ \\
LVEF $(\%)$ &
\end{tabular}

Data were expressed as mean \pm standard deviation $\&$ number and (\%)

Table showed gender distribution among total subjects with $32.3 \%$ females and $67.8 \%$ males.

Table (2): Relation between age and anthropometric characteristics of the study population

\begin{tabular}{|l|c|c|c|c|c|}
\hline \multicolumn{1}{|c|}{ Anthropometric } & $\begin{array}{c}\mathbf{1 6 - 3 0} \text { years } \\
(\mathbf{N}=\mathbf{3 0})\end{array}$ & $\begin{array}{c}\mathbf{3 0 - 5 0} \text { years } \\
(\mathbf{N}=\mathbf{3 0})\end{array}$ & $\begin{array}{c}>\mathbf{5 0 - 6 5} \text { years } \\
(\mathbf{N}=\mathbf{3 0})\end{array}$ & ANOVA & p-value \\
\hline Gender\# & $25(83.3 \%)$ & $19(63.3 \%)$ & $17(56.7 \%)$ & \multirow{2}{*}{5.291} & \multirow{2}{*}{0.042} \\
\hline Male & $5(16.7 \%)$ & $11(36.7 \%)$ & $13(43.3 \%)$ & & \\
\hline Female & $1.56 \pm 0.21^{\mathrm{a}}$ & $1.79 \pm 0.21^{\mathrm{b}}$ & $1.64 \pm 0.2^{\mathrm{c}}$ & 5.360 & $<0.001$ \\
\hline BSA (m2) & $70 \pm 12.5^{\mathrm{a}}$ & $67.5 \pm 10.5^{\mathrm{b}}$ & $62.5 \pm 9^{\mathrm{c}}$ & 8.140 & $<0.001$ \\
\hline HR (beats/min) & $119.5 \pm 10.5^{\mathrm{a}}$ & $123 \pm 13^{\mathrm{b}}$ & $128.5 \pm 12^{\mathrm{c}}$ & 7.082 & $<0.001$ \\
\hline Systolic BP $(\mathbf{m m H g})$ & $67.5 \pm 9^{\mathrm{a}}$ & $73.5 \pm 9^{\mathrm{b}}$ & $77 \pm 10^{\mathrm{b}}$ & 5.668 & $<0.001$ \\
\hline
\end{tabular}

Codes with difference litter indicate significant difference

F-ANOVA test; \# Chi-square test; p-value $<0.001$ highly significant

Data are expressed mean and standard deviation

This table showed statistically significant relation between age and anthropometric characteristics. Comparing between the three groups as regards mean body surface area, it showed 1.56 for first age group, 1.79 for second age group and 1.64 for last age group. The table showed decrease in mean heart rate with advanced age groups from 70 $\mathrm{b} / \mathrm{m}$ in first group to $67.5 \mathrm{~b} / \mathrm{m}$ in second age group to $62.5 \mathrm{~b} / \mathrm{m}$ in third age group. Also, it showed increase in mean systolic blood pressure with increased age groups from $119.5 \mathrm{mmHg}$ in first age group, then $123 \mathrm{mmHg}$ in second age group and up to $128.5 \mathrm{mmHg}$ in third age group. The mean diastolic blood pressure also increased with advancing age groups from $67.5 \mathrm{mmHg}$ in first age group to $73.5 \mathrm{mmHg}$ in second age group and $77 \mathrm{mmHg}$ in third age group. 
Table (3): Relation between age and Echocardiographic characteristics of the study population

\begin{tabular}{|l|c|c|c|c|c|}
\hline $\begin{array}{l}\text { Echocardiographic } \\
\text { Characteristics }\end{array}$ & $\begin{array}{c}\mathbf{1 6 - 3 0} \text { years } \\
(\mathbf{N}=\mathbf{3 0})\end{array}$ & $\begin{array}{c}\mathbf{3 0 - 5 0} \text { years } \\
(\mathbf{N}=\mathbf{3 0})\end{array}$ & $\begin{array}{c}\mathbf{5 0 - 6 5} \text { years } \\
(\mathbf{N}=\mathbf{3 0})\end{array}$ & ANOVA & p-value \\
\hline LVEDVI $(\mathrm{mL} / \mathrm{m} 2)$ & $51.07 \pm 2.53^{\mathrm{a}}$ & $52.13 \pm 2.05^{\mathrm{b}}$ & $53.90 \pm 1.95^{\mathrm{c}}$ & 12.79 & $<0.001$ \\
\hline LVESVI $(\mathrm{mL} / \mathrm{m} 2)$ & $28.43 \pm 2.74^{\mathrm{a}}$ & $31.33 \pm 2.34^{\mathrm{b}}$ & $35.50 \pm 1.87^{\mathrm{c}}$ & 68.97 & $<0.001$ \\
\hline LVEF $(\%)$ & $73.20 \pm 3.71^{\mathrm{a}}$ & $68.67 \pm 2.97^{\mathrm{b}}$ & $62.93 \pm 3.51^{\mathrm{c}}$ & 68.18 & $<0.001$ \\
\hline E $(\mathrm{cm} / \mathrm{sec})$ & $98.5 \pm 19^{\mathrm{a}}$ & $85 \pm 14^{\mathrm{b}}$ & $75.5 \pm 17.5^{\mathrm{c}}$ & 6.515 & $<0.001$ \\
\hline A $(\mathrm{cm} / \mathrm{sec})$ & $46 \pm 10.5^{\mathrm{a}}$ & $53.5 \pm 13^{\mathrm{b}}$ & $72.5 \pm 19.5^{\mathrm{c}}$ & 8.250 & $<0.001$ \\
\hline E/A ratio & $2.20 \pm 0.42$ & $1.64 \pm 0.37$ & $1.07 \pm 0.23$ & 7.971 & $<0.001$ \\
\hline DT $(\mathrm{msec})$ & $171 \pm 28.5^{\mathrm{a}}$ & $188.5 \pm 32^{\mathrm{b}}$ & $208 \pm 41^{\mathrm{c}}$ & 7.178 & $<0.001$ \\
\hline E/E' ratio & $7.89 \pm 1.36^{\mathrm{a}}$ & $8.15 \pm 1.4^{\mathrm{a}}$ & $10.45 \pm 2.7^{\mathrm{b}}$ & 11.663 & $<0.001$ \\
\hline
\end{tabular}

Codes with difference litter indicate significant difference

F-ANOVA test; $\mathrm{p}$-value $<0.001$ highly significant

Data are expressed mean and standard deviation

This table showed statistically significant relation between age and echocardiographic characteristics where there was increase in mean LVEDVI with advanced age groups from 51.07 $(\mathrm{ml} / \mathrm{m} 2)$ in first group to $52.13(\mathrm{ml} / \mathrm{m} 2)$ in second age group and $53.9(\mathrm{ml} / \mathrm{m} 2)$ in third age group. Also, it showed increase in mean LVESVI with increased age groups from $28.43(\mathrm{ml} / \mathrm{m} 2)$ in first group to 31.33 $(\mathrm{ml} / \mathrm{m} 2)$ in second age group and $35.5(\mathrm{ml} / \mathrm{m} 2)$ in third age group. The table showed decrease in mean $\mathrm{E}$ wave with advancing age groups from $98.5(\mathrm{~cm} / \mathrm{sec})$ in first group to $85(\mathrm{~cm} / \mathrm{sec})$ in second age group and 75.5 $(\mathrm{cm} / \mathrm{sec})$ in third age group. Also, it showed increase in mean A wave with advancing age groups from 46 $(\mathrm{cm} / \mathrm{sec})$ in first age group, then $53.5(\mathrm{~cm} / \mathrm{sec})$ in second age group and up to $72.5(\mathrm{~cm} / \mathrm{sec})$ in third age group. Moreover, this table showed increase in mean DT with advancing age from 171 (msec) in first age group, to 188.5 (msec) in second age group and up to 208 (msec) in third age group. Also, The table showed increasing mean of $E / E$ ' ratio with advancing age, ranging from 7.9 in the first age group, passing by 8.2 in second age group and finally 10.4 in last age group. Additionally, this table showed decreased mean of E/A ratio with advancing age, ranging from 2.2 in the first age group, passing by 1.64 in second age group and finally 1.07 in last age group.

Table (4): Relation between age and left ventricular longitudinal, circumferential, radial, 3D and Global Area strain of the study population

\begin{tabular}{|l|l|c|c|c|c|}
\hline Global & $\begin{array}{c}\mathbf{1 6 - 3 0} \text { years } \\
(\mathbf{N}=\mathbf{3 0})\end{array}$ & $\begin{array}{c}\mathbf{3 0 - 5 0} \text { years } \\
(\mathbf{N}=\mathbf{3 0})\end{array}$ & $\begin{array}{c}>\mathbf{5 0 - 6 5} \text { years } \\
(\mathbf{N}=\mathbf{3 0})\end{array}$ & ANOVA & p-value \\
\hline Longitudinal strain & $-19.2 \pm 1.52^{\mathrm{a}}$ & $-18.9 \pm 1.96^{\mathrm{b}}$ & $-17 \pm 0.99^{\mathrm{c}}$ & 107.83 & $<0.001^{* *}$ \\
\hline Circumferential strain & $-16.4 \pm 4.25$ & $-17.2 \pm 5.2$ & $-16.9 \pm 4.3$ & 0.134 & 0.762 \\
\hline Radial strain & $45.5 \pm 21.75$ & $43.7 \pm 22.5$ & $48 \pm 21.25$ & 1.656 & 0.219 \\
\hline 3D strain & $-22.07 \pm 1.48^{\mathrm{a}}$ & $-19.40 \pm 1.98^{\mathrm{b}}$ & $-17.67 \pm 1.52^{\mathrm{c}}$ & 52.61 & $<0.001^{* *}$ \\
\hline Global Area & $-29.1 \pm 1.31^{\mathrm{a}}$ & $-28.5 \pm 1.76^{\mathrm{b}}$ & $-28.1 \pm 1.65^{\mathrm{c}}$ & 178.23 & $<0.001^{* *}$ \\
\hline
\end{tabular}

Codes with difference litter indicate significant difference

F-ANOVA test; $p$-value $<0.001$ highly significant

Data are expressed mean and standard deviation 
Regarding age and left ventricular longitudinal strain of the study population, table 4 showed decrease in mean global longitudinal strain with advancing age from -19.2 in first age group, moving to -18.9 in second age group and then to -17 in third age group. The table showed that age and left ventricular circumferential strain increased in mean global circumferential strain with advancing age from -16.4 in first age group, moving to -17.2 in second age group and finally decreased to -16.9 in third age group. Besides, this table showed that age and left ventricular radial strain decreased in mean global radial strain with advancing age from 45.5 in first age group, moving to 43.7 in second age group, then increased up to 48 in third age group. Also, this table showed that age and left ventricular 3D strain decreased in mean global 3D strain with advancing age from -22.07 in first age group, moving to -19.4 in second age group and up to -17.67 in third age group. This table showed also that age and left ventricular global area strain decreased in mean global area strain with advancing age from -29.1 in first age group, moving to -28.5 in second age group and up to -28.1 in third age group.

\section{DISCUSSION}

One of the most significant developments of the last decades was the introduction of 3-dimensional (3D) imaging and its evolution from slow and labor-intense off-line reconstruction to real-time volumetric imaging.

The major proven advantage of this technique is the improvement in the accuracy of the echocardiographic evaluation of cardiac chamber volumes, which is achieved by eliminating the need for geometric modeling and the errors caused by foreshortened views ${ }^{(9)}$. A new technology called threedimensional wall motion tracking (3D-WMT) is capable of providing three dimensional (3D) images of the myocardium and obtains multiple measures of deformation, allowing for a complete assessment in very little time ${ }^{(\mathbf{1 0})}$.

The major findings of this study were as follows: Significant age dependency of 2D longitudinal, 3D longitudinal and area strain values was observed at the global levels of the left ventricle.

\section{Age-Related Changes in 3D Strain}

Controversy exists regarding the influence of age on global longitudinal strain. Using 2D STE, several studies ${ }^{(11)}$ reported reduction in longitudinal strain with increasing age, which is in agreement with our result. However, other studies have reported no age dependency of global longitudinal strain ${ }^{(12)}$. These discrepant results might partly be related to the different modalities, the software used for analysis, and the size of the study populations.

'In our study there was significant decrease in both global $3 \mathrm{~d}$ longitudinal strain and global area strain with advancing age. Area strain (AS) stands out as a particularly novel method with a high potential for clinical applications. This new parameter combines an analysis of both the longitudinal and circumferential deformation of the left ventricle. This provides an estimate of the subendocardial surface deformation, which is inversely proportional to the radial deformation (systolic thickening and diastolic thinning) of the ventricular wall, and is the first area of the endocardium to be affected in several different cardiopathies ${ }^{\left({ }^{(8)} \text {. }\right.}$

'The present study showed that the mean Global $3 \mathrm{D}$ strain at age group I, age group II and age group III were $-22.07 \pm 1.48 \%,-19.40 \pm 1.98 \%$ and $-17.67 \pm$ $1.52 \%$ respectively. Our study showed that the mean global longitudinal strain at age group I, age group II and age group III were $-19.2 \pm 1.52 \%,-18.9 \pm 1.96 \%$ and $17 \pm 0.99 \%$ respectively. Also this study showed that the mean global circumferential strain at age group I, age group II and age group III were $-16.4 \pm 4.25 \%,-17.2 \pm$ $5.2 \%$ and $-16.9 \pm 4.3 \%$ respectively. Additionally, this study showed that the mean Global radial strain at age group I, age group II and age group III were $45.5 \pm$ $21.75 \%, 43.7 \pm 22.5 \%$ and $48 \pm 21.25 \%$ respectively. Besides, The present study showed that the mean global area strain at age group I, age group II and age group III were $-29.1 \pm 1.31 \%,-28.5 \pm 1.76 \%$ and $-28.1 \pm 1.65 \%$ respectively. These results are in agreement with Tadic et al. ${ }^{(13)}$ who showed that the mean global area strain was $-28.2 \pm 3.8 \%$ in subjects who had no arterial hypertension, heart failure, coronary artery disease, previous cerebrovascular events, atrial fibrillation, congenital heart disease, valvular heart disease, obesity, neoplastic disease, cirrhosis of liver, kidney failure or endocrinological diseases including type 2 diabetes mellitus. Moreover, the present study results are in agreement with the results of Badano et al. ${ }^{(16)}$ who used three-dimensional speckle-tracking echocardiography to measure left ventricular myocardial strain in healthy subjects and the reference value for 3D global area strain in his study was $-29 \%$ to $-35 \%$, with $-26 \%$ as a lower limit of normality. Also the present study results are in agreement with Nesser et al. ${ }^{(14)}$ who measured 3D global area strain in patients after optimal repair of aortic coarctation and in healthy volunteers. The mean global area strain of the healthy volunteers was $-31.7 \pm 2.7 \%$. Our present study also correlates with the study of Ternacle et $\boldsymbol{a l} .{ }^{(15)}$ that showed that the mean age of the 25 competitive top-level athletes (rugby players) without left ventricular hypertrophy was $26 \pm 4$ year and their mean 3D global area strain was $-30 \pm 5 \%$ and the mean age of the twenty-five healthy subjects was 33 \pm 11 years with $-31 \pm 4 \%$ as mean value of $3 \mathrm{D}$ global area strain. 
Badano et al. (16) assessed the inter-vendor consistency of $3 \mathrm{D} \mathrm{LV}$ global strain values obtained using two different scanners in 60 patients $(38 \pm 12$ years, $64 \%$ males) with a wide range of LV end-diastolic volumes (from 74 to $205 \mathrm{~m} \mathrm{l}$ ) and ejection fractions (from 17 to $70 \%$ ). All of the patients underwent two 3D Left ventricular data set acquisitions using Vivid E9 and Artida ultrasound systems. global longitudinal, radial, circumferential and area strain values were obtained offline using the corresponding 3D STE softwares. Badano et al. (16) concluded that the inter-vendor agreement of radial, circumferential and area strain measured with Artida and VividE9 was poor. Reference values should be specific for each system and baseline and follow-up data in longitudinal studies should be obtained using the same 3D STE platform. Kouzu et al. (17) as well stated that values of three-dimensional LV strains by $3 \mathrm{D}$ speckle-tracking echocardiography are highly vendor- dependent.

Myocardial Strain analysis using speckletracking 3D echocardiography has shown interesting capabilities in the quantification of left ventricular systolic function particularly global area strain analysis. Seo et al. ${ }^{\left({ }^{18)}\right.}$ demonstrated area strain to be a useful tool in quantifying segmental function.

The present study established the mean and reference values for LV 3D global area strain parameter from a relatively big amount of healthy subjects. However, further studies are needed to define the normal values of area strain in light of the poor intervendor agreement and reproducibility of strain measurements. Our present study showed excellent intraobserver reproducibility of the results and an overall acceptable interobserver reproducibility of strain measurements. Besides, our results showed positive correlations between global area strain values and each of the global circumferential and global longitudinal Strain. A negative correlation was presented between global area strain and global radial strain, and this is in agreement with the results of Kowalik et $\boldsymbol{a l} .{ }^{(\mathbf{1 9})}$. Area strain seems a very promising new parameter which can be applied into routine clinical practice and this is in agreement with Galderisi et al. ${ }^{(20)}$ who used the new parameter of global area strain by three-dimensional (3D) echocardiography to study 38 native hypertensive patients. Galderisi et al. ${ }^{(20)}$ demonstrated that global area strain could detect early changes in myocardial function in these patients. Furthermore, global area strain was a comprehensive parameter of myocardial systolic deformation and was very sensitive to both changes of afterload and LV mass.

\section{CONCLUSION}

Global area strain derived from three-dimensional speckle-tracking may be applied clinically as a supplementary diagnostic method since strain imaging can identify LV dysfunction earlier than conventional methods. This opens a new perspective in heart failure prophylaxis and primary prevention with institution of therapeutic measures before the patients develop symptoms and irreversible myocardial dysfunction. The present study detected positive correlations between global area strain values and each of the global circumferential and global longitudinal strain. Negative correlations were detected between global area strain and each of the global radial strain and the ejection fraction.

\section{RECOMMENDATION}

Extensive clinical research to test the accuracy and prognostic value of 3D strain against reference standards is needed. One should remain aware of the pitfalls, which still exist and which are easily overlooked because of the easy one-click-gives-it-all approach of most software solutions.

Further development of strain imaging ought to be centered on even higher standardization of the methodology between completely different vendors, and therefore the current development of 3D strain ought to improve the diagnostic potential from the technology. Moreover, automatic image analysis that takes into consideration a lot of data than simply peak strain is anticipated to enhance the diagnostic power of strain imaging.

\section{REFERENCES}

1. Mor-Avi V, Lang RM, Badano LP et al. (2011): Current and evolving echocardiographic techniques for the quantitative evaluation of cardiac mechanics: ASE/EAE consensus statement on methodology and indications endorsed by the Japanese Society of Echocardiography. J A1n Soc Echocard iogr., 24: 277-31 3.

2. Strait JB, Lakatta EG (2012): Aging-associated cardiovascular changes and their relationship to heart failure. Heart Fail Clin., 8 (1): 143-164.

3. Saito K, Okura H, Watanabe $\mathrm{N}$ et al. (2009): Comprehensive evaluation of left ventricular strain using speckle tracking echocardiography in normal adults: Comparison of three-dimensional and two-dimensional approaches. J Ain Soc Echocardiogr., 22: 1025-1030.

4. Sorrentino R, Esposito R, Pezzullo E et al. (2016): Realtime three-dimensional speckle tracking echocardiography: technical aspects and clinical applications. Dovepress., 7: 147-158.

5. Reant P, Barbot L, Touche C et al. (2012): Evaluation of global left ventricular systolic function using threedimensional echocardiography speckle-tracking strain parameters. J Am Soc Echocardiogr., 25 (1): 68-79.

6. Maffessanti F, Nesser HJ, Weinert L et al. (2009): Quantitative evaluation of regional left ventricular function using three-dimensional speckle tracking echocardiography in patients with and without heart disease. Am J Cardiol., 104 (12): 1755-1762. 
7. Nemes A, Szántó G, Kalapos A et al. (2016): Reversal of left ventricular "rigid body rotation" during dipyridamoleinduced stress in a patient with stable angina: a case from the three-dimensional speckle tracking echocardiographic MAGYAR-Stress Study. Quant Imaging Med Surg., 6 (3): 308-311.

8. Pérez De Isla L, Balcones DV, Fernandez-Golfin C et al. (2009):Three-dimensional wall motion tracking: a new and faster tool for myocardial strain assessment: comparison with two-dimensional wall motion tracking. J Am Soc Echocardiogr., 22 (4): 325-330.

9. Mele D, Toselli T, Dal Monte A et al. (2008): Beyond dyssynchrony: what are the factors determining the response to cardiac resynchronization therapy [in Italian]? G Ital Cardiol (Rome), 9: 320-337.

10. Pérez De Isla L, Vivas D, Zamorano JL (2008): Threedimensional speckle tracking. Curr Cardiovasc Imaging Rep., 1 (1): 25-29.

11. Taqatqa A, Bokowski J, Al-Kubaisi M et al. (2016): The Use of Speckle Tracking Echocardiography for Early Detection of Myocardial Dysfunction in Patients with Duchenne Muscular Dystrophy. Pediatric Cardiology, 37 (8): 1422-1428.

12. Spethmann S, Dreger H, Schattke S et al. (2012): Twodimensional speckle tracking of the left ventricle in patients with systemic sclerosis for an early detection of myocardial involvement. European Heart JournalCardiovascular Imaging, 13 (10): 863-870.

13. Tadic M, Ilic S, Cuspidi C et al. (2015): Left ventricular mechanics in untreated normotensive patients with type 2 diabetes mellitus: a two- and three-dimensional Speckle Tracking study. Echocardiography, 32 (6): 947-955.
14. Nesser HJ, Mor-Avi V, Gorissen W et al. (2009): Quantification of left ventricular volumes using threedimensional echocardiographic speckle tracking: comparison with MRI. Eur Heart J., 30 (13): 1565-1573.

15. Ternacle J, Gallet R, Champagne $S$ et al. (2013): Changes in three-dimensional speckle-tracking-derived myocardial strain during percutaneous coronary intervention. J Am Soc Echocardiogr., 26 (12): 14441449.

16. Badano LP, Cucchini U, Muraru D et al. (2013): Use of three-dimensional speckle tracking to assess left ventricular myocardial mechanics: inter-vendor consistency and reproducibility of strain measurements. Eur Heart J Cardiovasc Imaging, 14 (3): 285-93.

17. Kouzu H, Yuda S, Muranaka A et al. (2011): Left ventricular hypertrophy causes different changes in longitudinal, radial and circumferential mechanics in patients with hypertension: a two-dimensional speckle tracking study. J Am Soc Echocardiogr., 24 (2): 192-199.

18. Seo Y, Ishizu T, Aonuma K (2014): Current status of 3dimensional speckle tracking echocardiography: a review from our experiences. J Cardiovasc Ultrasound, 22 (2): 49-57.

19. Kowalik E, Kowalski M, Klisiewicz A et al. (2016): Global area strain is a sensitive marker of subendocardial damage in adults after optimal repair of aortic coarctation: three-dimensional speckle-tracking echocardiography data. Heart Vessels, 31 (11): 1790-1797.

20. Galderisi M, Esposito R, Schiano-Lomoriello $\mathrm{V}$ et al. (2012): Correlates of global area strain in native hypertensive patients: a three-dimensional speckletracking echocardiography study. Eur Heart J Cardiovasc Imaging, 13 (9): 730-738. 